\title{
LABORATORY TESTING OF THE POTENTIAL FOR THE INFLUENCE OF SUSPENDED SEDIMENTS ON THE ELECTROCHEMICAL REMEDIATION OF KARST GROUNDWATER
}

\author{
Kimberly L. Hetrick \\ Northeastern University, Dept. of Civil and Environmental Engineering, 360 Huntington Ave., Boston, MA, 02115, \\ USA,hetrick.k@husky.neu.edu \\ Ljiljana Rajic \\ Northeastern University, Dept. of Civil and Environmental Engineering, 360 Huntington Ave., Boston, MA, 02115, \\ USA,l.rajic@neu.edu
}

\begin{abstract}
Akram N. Alshawabkeh
Northeastern University, Dept. of Civil and Environmental Engineering, 360 Huntington Ave., Boston, MA, 02115, USA,aalsha@neu.edu
\end{abstract}

Mohammad Shokri

University of Central Florida, Civil, Environmental, and Construction Engineering Dept., 12800 Pegasus Drive, Orlando,FL, 32816,USA, Shokri.m@knights.ucf.edu

\section{Dorothy J. Vesper}

West Virginia University, Dept. of Geology and Geography, 98 Beechurst Ave., Morgantown, WV, 26506, USA, djvesper@mail.wvu.edu

\begin{abstract}
Due to the complicated nature of karst aquifers, many groundwater treatment technologies are difficult to implement successfully. A particular challenge arises because sediments are ubiquitous and mobile in karst systems and may either facilitate contaminant transport or act as long-term substrates for storage via sorption. However, electrochemical remediation is a promising technology to be optimized for karst aquifers due to easy manipulation and control of groundwater chemistry as well as low cost, ability for in situ application, and performance under alternative power sources. This study investigates the effects of suspended karst sediments on the electrochemical remediation of groundwater via electro-Fenton (EF) mechanism. The EF mechanism relies on direct electrolysis (i.e., water electrolysis and ferrous iron release) and indirect, electrochemicallyinduced processes (i.e., $\mathrm{Pd}$ catalyzed $\mathrm{H}_{2} \mathrm{O}_{2}$ production). These processes can be optimized for $\mathrm{H}_{2} \mathrm{O}_{2}$ generation and support of its activation to hydroxyl radicals - a powerful oxidant capable of degrading and transforming a wide range of contaminants (e.g., chlorinated solvents). In this study, we tested sediments varying in concentrations of $\mathrm{Fe}, \mathrm{Mn}$ and buffering capacities. When the sediments were
\end{abstract}

introduced into the $\mathrm{EF}$ experiments, there were adverse effects on the $\mathrm{H}_{2} \mathrm{O}_{2}$ content: at steady state $(120 \mathrm{~min}), \mathrm{Pd}$ catalyzed formation of $\mathrm{H}_{2} \mathrm{O}_{2}$ decreased by $60 \%, 57 \%$, and $75 \%$ in the presence of suspended sediment collected from three separate karst locations. Presented results imply that sediments' presence influences EF mechanism in electrochemical systems, but given the flexibility of the technology, it can be optimized in terms of electrode materials, current intensities and current regimes to address these challenges.

\section{Introduction}

Groundwater pollution is one of the greatest and most challenging environmental problems around the world. Toxic pollutants, defined by the EPA as those that cause death, disease, behavioral abnormalities, cancer, genetic mutations, physiological malfunctions (including malfunctions in reproduction) or physical deformations, are introduced into the environment through a variety of mediums, including mining activities, agriculture, manufacturing, vehicle emissions, improper disposal of chemicals, and more. (USEPA). As of 2009, an estimated two billion people drank polluted groundwater or breathed in toxic gases daily (Kuppusamy et al., 2016). 
In response to rising pollution levels, groundwater remediation technologies continue to evolve to remove contaminants in a safe, efficient, and cost-effective manner. One emerging technology that appears favorable is that of electrochemical groundwater remediation, due to its versatility, ability to be easily controlled, costeffectiveness, and ability to be performed in situ. The electrochemical cells can be optimized to treat a wide range of contaminants, including chlorinated compounds such as trichloroethylene (Acar et al., 1993; Rajic et al., 2016; Yuan et al., 2012). Recent field work using electrolytic reactive barriers to degrade chlorinated solvents has found their use effective, as electrode materials (titanium MMO) lifetimes are long-lasting, necessary power supplies are low (6 amps/m2), polarity reversal removes buildup of precipitates, and ultimately $90 \%$ of TCE in the field study was degraded without the formation of VC and DCE (Gilbert et al., 2010).

In particular, karst aquifers are susceptible to pollution due to direct recharge from sinkholes and other areas while challenges in implementing conventional remediation methods arise from complexity of terrain and geochemistry (Vesper et al., 2000). While electrochemical remediation implementation in karst systems requires additional investigation due to their complex nature and high flow volumes, electrochemical systems are being considered for karst aquifers, due to ease of manipulation and control of groundwater chemistry. Moreover, this technology has the potential to be modified for ex situ point-of-use treatment in locations where complex or heterogeneous aquifers make in-situ treatment difficult.

One mechanism currently studied for contaminant degradation through the electrochemical systems is oxidation via hydroxyl radicals $(\bullet \mathrm{OH}$.) Oxygen gas produced at the anode (Eq. 1) of the reactor reacts with hydrogen gas produced at the cathode (Eq. 2), catalyzed by the presence of palladium. $\mathrm{H}_{2} \mathrm{O}_{2}$ is formed (Eq. 3), which is then catalyzed to form $\cdot \mathrm{OH}$ in the presence of ferrous iron at low $\mathrm{pH}$ values (Eq. 4), in a process known as the Fenton reaction. The hydroxyl radicals, which are strong oxidants, non-discriminately degrade organic contaminants (Yuan et al., 2012).

$$
\begin{aligned}
& 2 \mathrm{H}_{2} \mathrm{O} \rightarrow \mathrm{O}_{2}+4 \mathrm{H}^{+}=4 e^{-} \\
& \mathrm{H}_{2} \mathrm{O}+2 e^{-} \rightarrow \mathrm{H}_{2}+2 \mathrm{OH}^{-}
\end{aligned}
$$

$$
\begin{array}{lr}
\mathrm{H}_{2}+\mathrm{O}_{2}(+\mathrm{Pd}) \rightarrow \mathrm{H}_{2} \mathrm{O}_{2} & \text { Eq. } 3 \\
\mathrm{H}_{2} \mathrm{O}_{2}+\mathrm{Fe}^{I I}+\mathrm{H}^{+} \rightarrow \mathrm{Fe}^{I I I}+\bullet \mathrm{OH}+\mathrm{H}_{2} \mathrm{O} & \text { Eq. } 4
\end{array}
$$

Though the electrochemical mechanism can be optimized for maximum degradation efficiency in laboratory settings for given flow rates, electrode materials, currents, and electrolytic solutions, advanced oxidation processes are found to be influenced by naturally occurring substances (Austin et al., 2013). Specifically, Sra et al. (2010) found that, though the reaction rates were low, the presence of natural aquifer materials affected the concentrations of persulfate, a highly oxidizing chemical oxidant, relative to laboratory controls.

In particular, suspended sediments have been shown to be present in natural karst groundwater in turbidities from 0 NTU up to 200 NTU during storm events, and can reach up to 1000 NTU in sinkhole vicinities (Dussart-baptista et al., 2003; Pronk et al., 2006; Pronk et al., 2009). Due to the abundance of suspended sediments in natural karst systems, their presence during electrochemical treatments must be considered if the technology is to be used for the remediation of karst systems.

The purpose of this paper is to determine the effects that suspended sediments play on the creation of oxidizing species in an electrochemical flow-through reactor.

\section{Materials and Methods Materials}

All chemicals used in this study were above analytical grade. $\mathrm{CaSO}_{4}$ was purchased from $\mathrm{J}$ T Baker. $\mathrm{Na}_{2} \mathrm{SO}_{4}$ and $\mathrm{H}_{2} \mathrm{SO}_{4}$ were purchased from Fisher Scientific. $\mathrm{NaOH}$ was purchased from ACROS. Palladium pellets ( $0.5 \%$ wt. Pd on alumina pellets) were purchased from Alfa Aesar. Titanium sulfate $\left(\mathrm{TiSO}_{4}\right)$ was purchased from GFS Chemicals. Deionized water $(18.0 \mathrm{~m} \Omega \mathrm{cm})$ obtained from a Millipore Milli-Q system was used in all the experiments.

Simulated groundwater was created by mixing $3 \mathrm{mM}$ $\mathrm{Na}_{2} \mathrm{SO}_{4}$ and $0.5 \mathrm{mM} \mathrm{CaSO}_{4}$ in deionized water. Carbonates and bicarbonates were excluded from this study to decouple their effects on the electrochemical processes from the effects of suspended sediment, although $\mathrm{H}_{2} \mathrm{O}_{2}$ formation and the Fenton reaction are also expected to be affected by the high buffering capacity of karst groundwater. 
Three sediment samples were collected from karst deposits in West Virginia. The samples, denoted as MC, DLC, and CTS, were sifted through $1.18 \mathrm{~mm}$ mesh before introducing into the reactor. Suspended sediment mixtures were mixed for two days before use; this is the amount of time necessary to reach chemical equilibrium.

\section{Electrochemical Setup}

A vertical acrylic column (Figure 1) was used as plug flow electrochemical reactor. Three titanium/ mixed metal oxide (Ti/MMO) electrodes were assembled in a sequence of anode, cathode 1, and cathode 2, from the bottom to the top of the reactor. Directly on the top of cathode 1 was one layer of glass beads, to prevent palladium/electrode direct reactions, on top of which was placed $10 \mathrm{~g}$ of palladium pellets $\left(\mathrm{Pd} / \mathrm{Al}_{2} \mathrm{O}_{3}\right)$. A constant current of $90 \mathrm{~mA}$ was supplied to the electrodes by DC source. Current was split between cathode 1 and cathode 2 at a corresponding ratio of 2:1 to optimize $\mathrm{H}_{2} \mathrm{O}_{2}$ production, based on prior experimental tests (data not yet published).

A constant flow rate of $5 \mathrm{~mL} / \mathrm{min}$ was maintained by a peristaltic pump during 2 hours of experiment, when steady state was reached. The simulated groundwater with or without $2 \mathrm{~g} / \mathrm{L}$ of suspended sediment (roughly between 100 and 1000 NTU, depending on the sediment sampling site) was supplied to the reactor. The samples

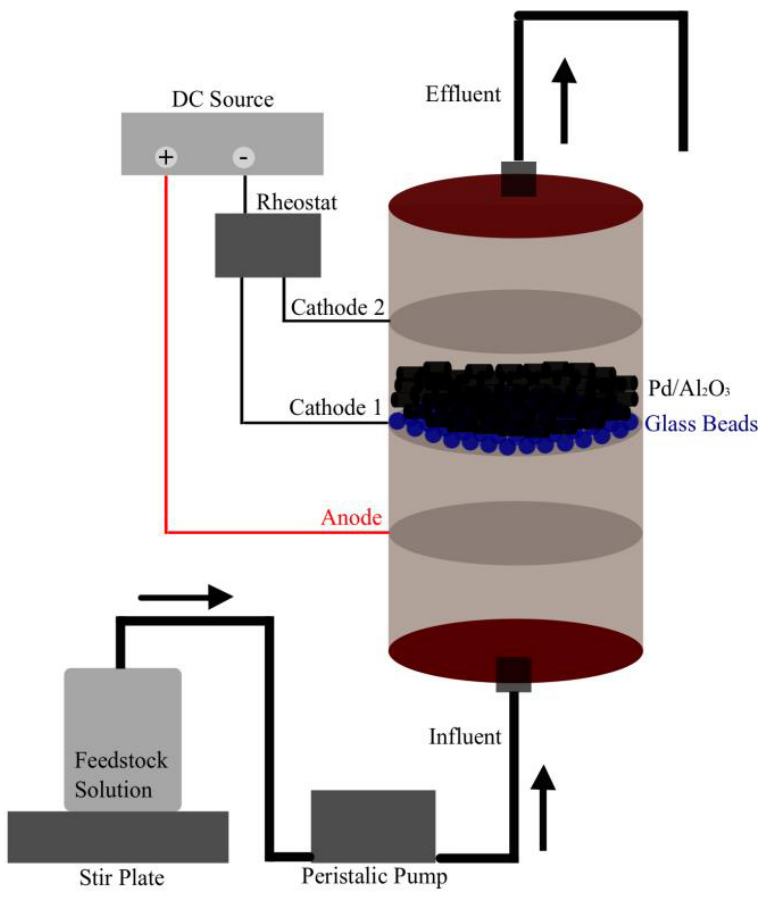

Figure 1. Electrochemical column setup. were taken from the defined sampling ports and analyzed for $\mathrm{H}_{2} \mathrm{O}_{2}$ content and $\mathrm{pH}$. Experiments were conducted in duplicates.

\section{Experimental Methods}

$\mathrm{H}_{2} \mathrm{O}_{2}$ concentration was measured spectrophotometrically according to the method described by Eisenberg (1943). Samples containing suspended sediment were filtered through $0.22 \mu \mathrm{m}$ Milipore filters prior to analysis. Excluding the removal of suspended sediment particles from solution, filtering revealed to have no additional effect on the $\mathrm{H}_{2} \mathrm{O}_{2}$ measurements (such as lowering $\mathrm{H}_{2} \mathrm{O}_{2}$ measurements relative to non-filtered samples).

Titrations were performed by raising the $\mathrm{pH}$ of $100 \mathrm{~mL}$ of $2 \mathrm{~g} / \mathrm{L}$ of suspended sediment samples to 10 by the addition of $<1 \mathrm{~mL} 0.1 \mathrm{M} \mathrm{NaOH}$. The $\mathrm{pH}$ was brought to 3 using $0.01 \mathrm{M} \mathrm{H}_{2} \mathrm{SO}_{4}$.

Specific conductance (SC) and $\mathrm{pH}$ were measured on slurries shaken at $100 \mathrm{rpm}$ for 1 hour. Following the methods of Kalra (1995) and Hanlon (2015), 1:1 sediment-water ratio was used for $\mathrm{pH}$ and a 1:2 ratio for $\mathrm{SC}$; replicates of six samples were measured.

\section{Instruments}

$\mathrm{H}_{2} \mathrm{O}_{2}$ concentration was measured using a Shimadzu UV1800 spectrophotometer. The $\mathrm{pH}$ of the solution during electrochemical experiments was measured using a portable Orion 3-Star $\mathrm{pH}$ meter. $\mathrm{SC}$ and $\mathrm{pH}$ of intrinsic sediment samples were measured using calibrated Hanna Instruments laboratory electrodes. Metal concentration was determined through inductively coupled plasma mass spectrometry (ICP-MS, Bruker Aurora M90) Turbidity was measured using a HACH $2100 \mathrm{~N}$ turbidity-meter.

\section{Results and Discussion Sediment Chemistry}

Prior to running the column experiments, sediment samples were examined for all relevant intrinsic characteristics. Specific conductance was determined to be an average of 44.78, 69.63, and $86.12 \mu \mathrm{S} / \mathrm{cm}$ for MC, DLC, and CTS, respectively. The $\mathrm{pH}$ was determined to be an average of 7.70, 7.74, and 6.77 for MC, DLC, and CTS, respectively. Both SC and pH data are depicted in Figure 2.

The suspended sediment samples were additionally tested for turbidity and metal concentrations ( $\mathrm{Mn}$ and $\mathrm{Fe}$ ) using $2 \mathrm{~g} / \mathrm{L}$ of the sample. The turbidity measurements 
indicated that CTS sample contains the largest number of smaller size fractions (Table 1). This is consistent to grain size analyses, not included in this study. CTS also contains the largest concentration of dissolved manganese, while DLC contains the largest concentration of dissolved iron. Both metals could play a role in the conversion of $\mathrm{H}_{2} \mathrm{O}_{2}$ in the reactor to hydroxyl radicals (Oturan et al., 2010).

As shown in Figure 3, all sediment types followed similar titration trends, although CTS was slightly dissimilar to the other two sediment types due to its increased resistance to $\mathrm{pH}$ changes throughout the entire titration. This increased buffering capacity could lead to greater $\mathrm{pH}$ resistances in the plug flow reactor, as is discussed in the following section.

\section{Plug-Flow Experiments}

The results of the plug flow $\mathrm{H}_{2} \mathrm{O}_{2}$ tests are displayed in Figure 4. The results show that the suspended sediments have a negative effect on the amount of $\mathrm{H}_{2} \mathrm{O}_{2}$ in the reactor during the experiments (Figure 4). At steady state (120 minutes), the $\mathrm{H}_{2} \mathrm{O}_{2}$ concentrations in solutions containing $2 \mathrm{~g} / \mathrm{L}$ of MC, DLC, and CTS were $60 \%, 57 \%$, and $75 \%$ lower than the control tests, respectively.

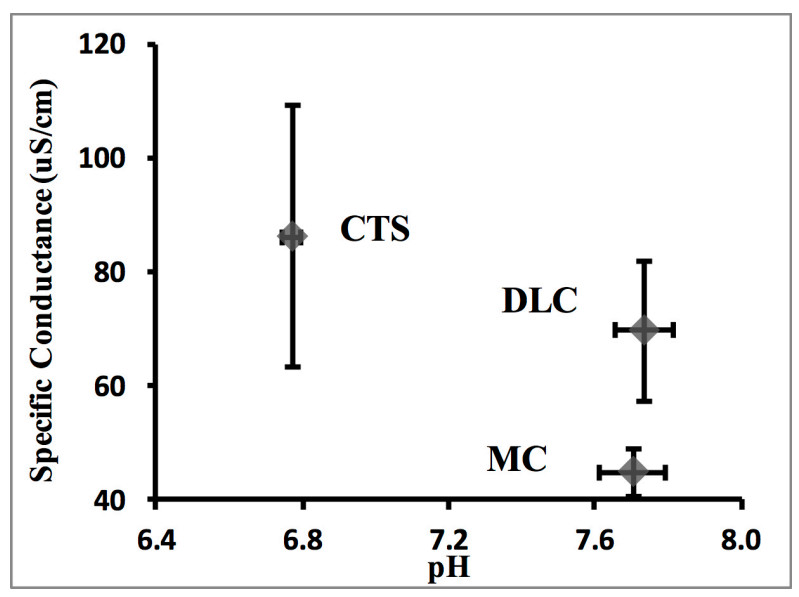

Figure 2. Specific conductance and $\mathrm{pH}$ of sediment samples MC, DLC, and CTS.

\begin{tabular}{|l|c|c|c|}
\hline Sediment site & Mn (ppb) & Fe (ppb) & Turbidity (NTU) \\
\hline MC & 4.1 & 31.8 & 140 \\
\hline DLC & 2.35 & 37.5 & 52 \\
\hline CTS & 47.8 & 32.5 & 1254 \\
\hline
\end{tabular}

Table 1. Leached $\mathrm{Mn}$ and Fe, and Turbidity of $2 \mathrm{~g} / \mathrm{L}$ of suspended sediments from MC, DLC, and CTS sampling sites

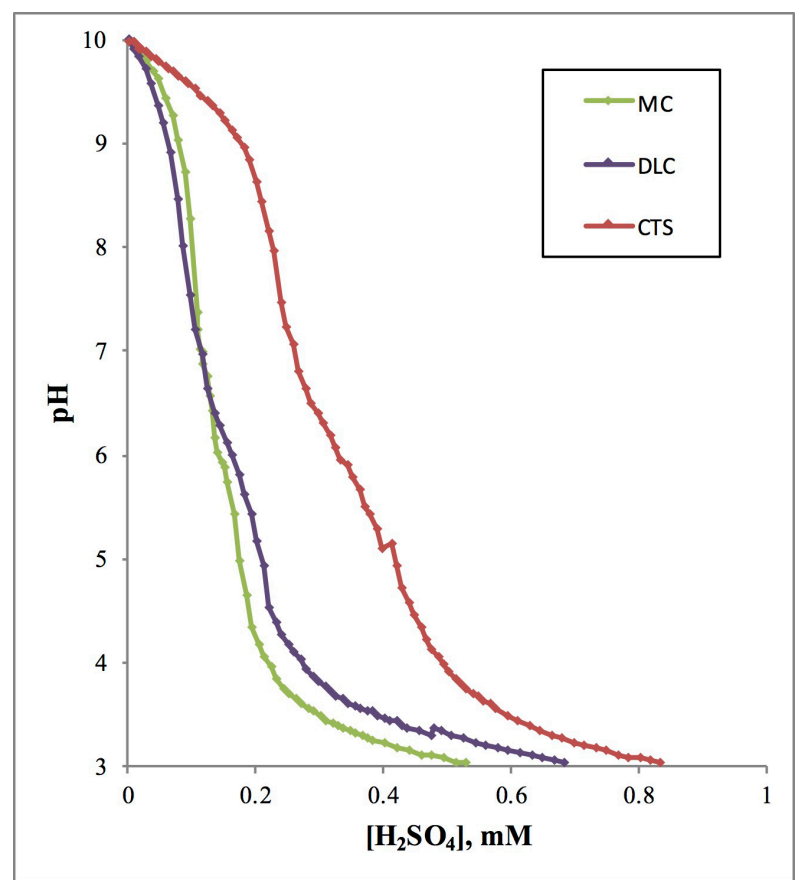

Figure 3. Titrations of CTS, DLC, and MC sediment samples from $\mathrm{pH} 10$ to $\mathrm{pH} 3$.

The $\mathrm{pH}$ of the solution above the anode, cathode 1, and cathode 2, is displayed in Figure 5. Though the $\mathrm{pH}$ of the solution is more variable in the vicinity above cathode 1 for all sediment types, it appears that the buffering capacities of the differing sediment types do not affect their respective $\mathrm{pH}$ values in the cathode or the variability of the $\mathrm{pH}$ values.

\section{Discussion}

Suspended sediment in high concentrations has a negative impact on $\mathrm{H}_{2} \mathrm{O}_{2}$ formed during the electrochemical process used to oxidize contaminants, and can lower the production up to $75 \%$ relative to a control.

Possible sources of suspended sediment interference in $\mathrm{H}_{2} \mathrm{O}_{2}$ production include: (1) covering of the palladium and electrodes with fine particles of sediment, impeding $\mathrm{H}_{2} \mathrm{O}_{2}$ formation, (2) the catalyzed breakdown of $\mathrm{H}_{2} \mathrm{O}_{2}$ into water due to the presence of suspended sediments, and (3) increasing the production of hydroxyl radicals from $\mathrm{H}_{2} \mathrm{O}_{2}$, catalyzed by manganese and iron from the sediments.

Based on the preliminary tests (not included in this paper) suspended sediments accumulate on the electrodes during the course of the experiments but the coverage of the anode and cathode negligibly change $\mathrm{H}_{2} \mathrm{O}_{2}$ content. 
The $\mathrm{pH}$ of the solution in the column ranged between $\sim 2.5$ above the anode to $\sim 10.5$ above cathode 2 . Maintaining the $\mathrm{pH}$ zones within the reactor is of great importance for efficient electro-Fenton reaction (optimum $\mathrm{pH}$ is 3 ). While the sediment samples displayed differing buffering capacities in relevant $\mathrm{pH}$ values, the spatial variability

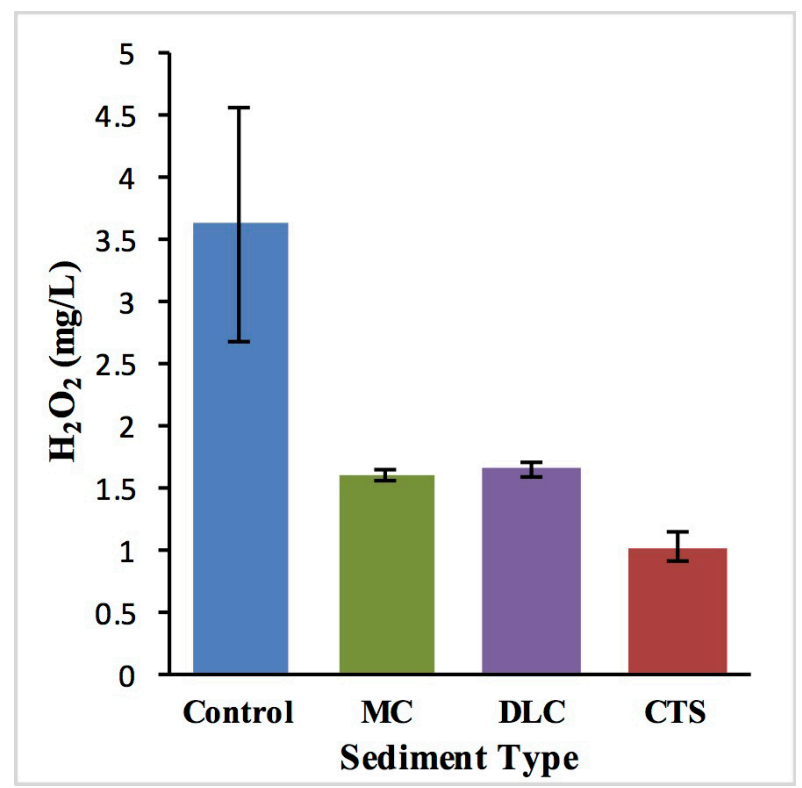

Figure 4. Concentration of $\mathrm{H}_{2} \mathrm{O}_{2}$ at the steady state flow rate condition measured after 120 minutes using $2 \mathrm{~g} / \mathrm{L}$ of suspended sediment. Error bars depict one standard deviation from average values.

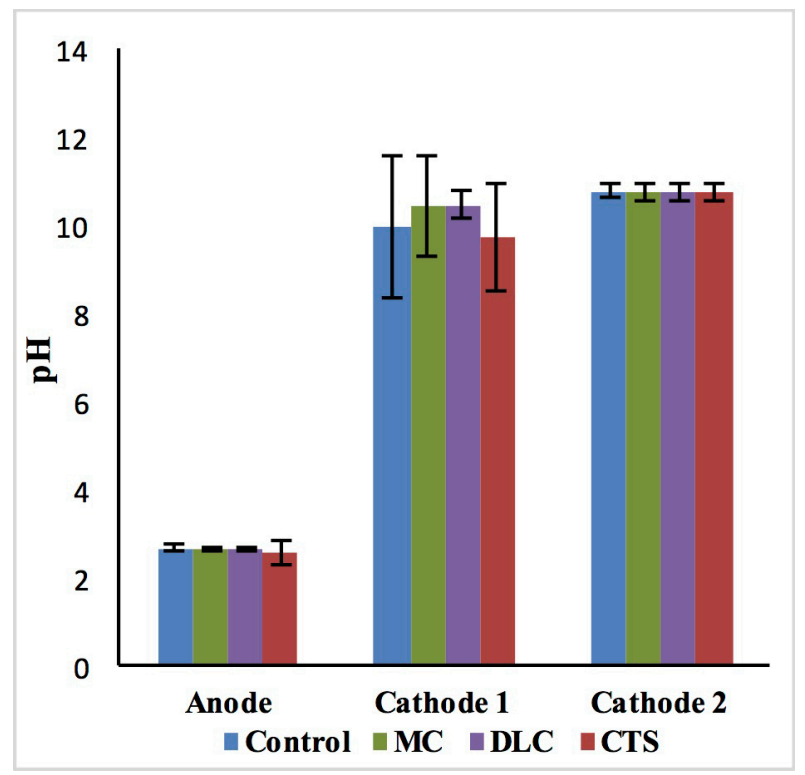

Figure 5. Column experiment $\mathrm{pH}$ values above the anode, cathode 1, and cathode 2. Error bars depict one standard deviation from average values. of $\mathrm{pH}$ values throughout the column in the presence of different sediment types did not differ significantly from the control (maximum of $\pm 1.2 \mathrm{pH}$ units in cathode 1 vicinity). Therefore, the influence of innate buffering capacities of sediments appears to negligibly affect the $\mathrm{pH}$ profile of solution in the electrochemical column.

An additional influence of $\mathrm{pH}$ relates to the breakdown of $\mathrm{H}_{2} \mathrm{O}_{2}$ in the presence of suspended sediment, where at $\mathrm{pH} 10, \mathrm{H}_{2} \mathrm{O}_{2}$ decreases up to $35 \%$, while at $\mathrm{pH} 4$ changes are negligible. These data (not shown here) are part of an ongoing study on the effects of sediments on batch experiments, and may be a factor in the lower concentrations of hydrogen peroxide measured in the column reactor in the presence of sediments.

Future work will include investigation into concentrations of redox species ( $\mathrm{Mn}$ and $\mathrm{Fe}$ ) catalyzing $\mathrm{H}_{2} \mathrm{O}_{2}$ degradation into hydroxyl radicals. Though the concentrations of redox species from the suspended sediments samples were low (Table 1), further tests including the direct measurement hydroxyl radicals will confirm if this metal presence due to the presence of suspended sediments contributes to the production of these highly oxidizing species.

Ongoing and future work focuses more thoroughly on the mechanisms affected by the suspended sediments in order to identify weak spots and optimize the electrochemical oxidation/reduction of contaminants in the presence of large amounts of suspended sediments. Future work will include breakdown of contaminants such as trichloroethylene and pesticides in the presence of suspended sediments to determine if the presence of sediments affects contaminant degradation.

\section{Acknowledgements}

This work was supported by the US National Institute of Environmental Health Sciences (NIEHS, Grant No. P42ES017198). The content is solely the responsibility of the authors and does not necessarily represent the official views of the NIEHS or the National Institutes of Health.

\section{References}

Acar Y, Alshawabkeh A. 1993. Principles of

Electrokinetic Remediation. Environmental

Science \& Technology 27 (13): 2638-2647.

Austin O, Hart J, Jarvis P, MacAdam J, Parsons S, Jefferson B. 2013. The Impact of Background 
Organic Matter and Alkalinity on the Degradation of the Presticide Metaldehyde by Two Advanced Oxidation Processes: UV/H2O2 and UV/TiO2. Water Research 47: 2041-2049.

Dussart-Baptista L, Massei N, Dupont J, Jouenne T. 2003. Transfer of bacteria-contaminated particles in a karst aquifer: evolution of contaminated materials from a sinkhole to a spring. Journal of Hydrology 284: 285-295.

Eisenberg G. 1943. Colorimetric Determination of Hydrogen Peroxide. Industrial \& Engineering Chemistry Analytical Edition 15 (5): 327-328.

Gilbert D, Sale T, Peterson M. 2010. Electrolytic Reactive Barriers for Chlorinated Solvent Remediation. In: Stroo HF, Ward CH, editors. In Situ Remediation of Chlorinated Solvent Plumes. New York (NY): Springer. p. 573-590.

Hanlon EA. 2015. Soil pH and Electrical Conductivity: A County Extension Soil Laboratory Manual. U Florida Institute of Food and Agricultural Sciences, Publication \#CIR1081.

Kalra Y. 1995. Determination of $\mathrm{pH}$ of soils by different methods: collaborative study. Journal of AOAC International 78 (2): 310-324.

Kuppusamy S, Palanisami T, Megharaj M, Venkateswarlu K., Naidu R. 2016. In-situ remediation approaches for the management of contaminated sites: A comprehensive overview. Reviews of Environmental Contamination and Toxicology 236: 1-115.

Oturan N, Zhou M, Oturan MA. 2010. Methomyl degradation by electro-Fenton and electro-Fentonlike processes: a kinetics study of the effect of the nature and concentration of some transition metal ions as catalyst. J Phys Chem 114: 10605-10611.

Pronk M, Goldscheider N, Zopfi J. 2006. Dynamics and interaction of organic carbon, turbidity and bacteria in a karst aquifer system. Hydrogeology Journal 14: 473-484.

Pronk M, Goldscheider N, Zopfi J. 2009. Percolation and Particle Transport in the Unsaturated Zone of a Karst Aquifer. Ground Water 47 (3): 361-369.

Rajic L, Nazari R, Fallahpour N, Alshawabkeh AN. 2016. Electrochemical degradation of trichloroethylene in aqueous solution by bipolar graphite electrodes. Journal of Environmental Chemical Engineering 4 (1): 197-202.

Sra K, Thomson N, Baker J. 2010. Persistence of Persulfate in Uncontaminated Aquifer Materials. Environmental Science \& Technology 44 (8): 3098-3104.

Clean Water Act, Section 502 General Definitions [Internet]. [U.S. EPA]: epa.gov; [Cited 2017
August 29]. Available from: https://www.epa.gov/ cwa-404/clean-water-act-section-502-generaldefinitions.

Vesper DJ, Loop CM, White WB. 2000. Contaminant Transport in Karst Aquifers. Theoretical and Applied Karstology 13: 63-73.

Yuan S, Mao X, Alshawabkeh AN. 2012. Efficient Degradation of TCE in Groundwater Using Pd and Electro-generated $\mathrm{H}_{2}$ and $\mathrm{O}_{2}$ : A Shift in Pathway from Hydrodechlorination to Oxidation in the Presence of Ferrous Ions. Environmental Science \& Technology 46: 3398-3405. 